\title{
Investigating the Chronological Variation of Popular Song Lyrics Through Lexical Indices
}

\author{
Yuichiro Kobayashi ${ }^{1}$, Misaki Amagasa ${ }^{* *}$, and Takafumi Suzuki ${ }^{* *}$
}

\begin{abstract}
Popular songs can be regarded as a fine representation of modern society and culture. In particular, the lyrics of popular songs are the most important aspect for understanding the sense of values and linguistic sensitivity in a given generation and community. The purpose of the present study is to investigate the chronological variation of popular Japanese songs using stylometric techniques. This study draws on the lyrics of 858 songs, which appeared on the Oricon annual top 20 single hit chart between 1976 and 2015. The linguistic features investigated in this study include five different types of lexical indices, namely (a) number of words, (b) parts-of-speech, (c) word types, (d) character types, and (e) vocabulary level. Multiple regression analysis was conducted to explore the chronological change in the frequencies of lexical indices. The results showed that the frequencies of word types and character types dramatically changed before and after 1990. Moreover, the usages of auxiliary verbs as well as lower level vocabulary became more prominent, whereas the frequencies of adjectival nouns and conjunctions decreased. The findings suggest that a turning point in cultural trends corresponds with the historically significant political and economic events, such as the end of the Showa era and the burst of the bubble economy.
\end{abstract}

\section{Introduction}

Popular songs provide a special kind of window into modern society and culture. In the United States, a number of people listen to top-ranked songs on the Billboard chart, and many songwriters make an effort to compose songs that can reach not just domestic listeners but also overseas fans. This tendency can be observed in many other countries, including Japan, where people are enthusiastic about songs that are highly ranked on the Oricon Chart. Multiple factors attract listeners to their favorite music: rhythm, melody,

\footnotetext{
1 Nihon University

${ }^{* *}$ Toyo University
} 
harmony, and lyrics. Among these, lyrics are the most important for understanding the sense of values and linguistic sensitivity of a given generation and community. They are essential in conveying the message from writers and singers to listeners, as well as emphasizing the message for the listeners. Given that people project their own feelings into the lyrics of a song by singing or humming it, lyrics are closely related to the atmosphere of the society and time in which they gain popularity. Although the themes and styles of lyrics vary according to individual artists and songs, they clearly reflect people's sense of values and tend to reflect the time in which they were created. Analyzing the lyrics of popular songs, therefore, is a significant step in comprehending the historical background and psychological condition of people living in a particular place and time.

\section{Literature Review}

\subsection{English Lyrics}

Lyrics as a social representation have received considerable attention in the field of sociology. In particular, the themes of love and gender have been at the core of studies on English lyrics. By investigating 235 different lyrics, Horton (1957) showed that the most popular topic of popular songs is romance between men and women. He also reported that the content of love songs differs depending on the genre of music. For example, courtship is the principal theme in hit songs whereas loneliness is the chief motif in country music. Similarly, Carey (1969) revealed changes in perspective with regard to the relationship between boys and girls by comparing the lyrics of songs published in 1955 and 1966. In rock-and-roll poetry released in the 1960s, love was no longer a romantic involvement but a physical desire. Mooney (1968) tracked the thematic change in popular music from the 1920 s to 1960 s, concluding that the emergence of a sexually casual generation led to a decrease in sentimental love songs.

Researchers have also focused on the linguistic aspects of lyrics using computerassisted content analysis. For instance, Wilkinson (1976) examined the difference in frequencies of verbs and adjectives between the genders of subjects, and pointed out that descriptions of men and women in the lyrics reflect conventional sex-role expectations. Bértoli-Dutra (2014) also shed light on the difference in the use of multiword expressions among sixteen different music styles or genres by comparing 6,290 American and British popular songs released from 1940 to 2009. A blogger for a ticket-selling company, SeatSmart, investigated the difficulty of sentences in lyrics from 225 songs that topped American charts from 2005 to 2014, showing that the words and sentences used in American hit songs become markedly simpler and easier to read over the period of a 
decade (Powell-Morse 2015). Further, the results showed that the lyrics of songs by a Canadian heavy metal band are easier to understand than writing for first-year students in the US.

\subsection{Japanese Lyrics}

Various studies of Japanese popular music are aimed at identifying the sociocultural ideas and concepts of specific times. For example, Mita (1968) investigated the chronological changes in Japanese peoples' thought before and after the World Wars by analyzing 451 songs from 1868 to 1963 , in order to identify emotional factors such as anger, joy, loneliness, and longing. Following the methodology used in this study, Sako (2015) described the chronological changes that have been occurring in Japanese hit song lyrics through the years 1968-2013, and clarified the difference in lyrics between the twentieth and twenty-first centuries. Further, Kubo (1995) set up an archive of 302 popular songs from 1965 to 1989 and showed that youth-themed songs (in Japanese, wakamono-mono, songs about young people) decreased in popularity after 1975, whereas love songs gained popularity.

The linguistic analysis of Japanese lyrics started with Mizutani (1982), who applied multivariate statistical analyses to identify similar usages of words in Japanese popular songs in the beginning of the Showa era (1926-1989). After that landmark study, Ito (1997-2000) linguistically analyzed the lyrics of a famous Japanese singer-songwriter, Yumi Matsutoya. Furthermore, Suzuki and Hosoya (2014) examined the lyrics of songs by multiple female singers using machine learning techniques. Although there are many other studies focusing on specific artists or genres in the Heisei era (1989- ), few studies have attempted comprehensive descriptions of a wider variety of popular lyrics in multiple generations to observe the macroscopic shifts and changes in cultural trends. In order to fill the gap, this study aims to identify the chronological changes in language use in lyrics during four decades by diachronically analyzing Japanese popular songs released from 1976 to 2015.

\section{Research design}

\subsection{Data}

The present study draws on data consisting of the lyrics of songs ranked in the top twenty 
on the annual Oricon single chart from 1976 to $2015 .^{2}$ Songs from the same double Aside single are counted separately. If a song was ranked on the chart for several years, the first year that it was ranked is considered the target. Sixteen songs for which the lyrics could not be obtained from the websites Uta Net, ${ }^{3}$ Uta Map, ${ }^{4}$ and J-Lyrics.net ${ }^{5}$ before May 2016 were excluded. As a result, the number of songs analyzed was 858 . Table 1 summarizes the data used in this study.

Table 1. Summary of the Data

\begin{tabular}{lr}
\hline Total number of letters & 611,244 \\
Total number of words & 314,267 \\
Total number of sentences & 7,505 \\
\hline
\end{tabular}

Notes. All numbers shown in this table were calculated using MeCab $0.996^{6}$ and UniDic 2.2.0. ${ }^{7}$

\subsection{Linguistic Features}

Previous linguistic studies on popular songs have focused primarily on words used in lyrics. While Kobayashi, Kano, and Suzuki (2013) analyzed all the types of words used in texts, other researchers targeted only specific words for analysis. Kinjo (2013) and Suzuki and Hosoya (2014) focused on high frequency words, whereas others analyzed nouns and verbs (Kayane 2002), verbs (ibid.), pronouns (ibid.; Fujikake et al. 1994; Fujikawa 1999), sentence-final expressions (Suzuki and Yamaguchi 2000), collocations (T. Tsukamoto 2014), the combinations of kanji and kana readings (Suzuki and Yamaguchi 2000), and expressions in English (Fujikake et al. 1994). Regardless of targeted linguistic features, all of these studies merely analyzed the surface forms of vocabulary, not their lemmatizations.

This study, in contrast, investigates the vocabulary in lyrics by using twenty-six different lexical indices consisting of (a) parts of speech, (b) word types, (c) character types, and (d) vocabulary levels (see table 2). The effectiveness of these indices for computational stylistics has been demonstrated by a wide array of previous studies (e.g.,

\footnotetext{
2 Some of these data were compiled by Amagasa (2014) in order to identify differences in lyrics according to genre.

3 Accessed July 3, 2017, http://www.uta-net.com/.

4 Accessed July 3, 2017, http://www.utamap.com/.

5 Accessed July 3, 2017, http://j-lyric.net/.

${ }^{6}$ http://taku910.github.io/mecab/.

7 http://osdn.jp/projects/unidic/.
} 
Kabashima and Jugaku 1965; Yasumoto 1958, 1965). However, no studies have ever applied this set of linguistic features to the systematic analysis of Japanese lyrics. Considering that the results of linguistic analysis of lyrics are susceptible to their contents because of the small number of words they contain compared with other text genres, the present study used the above lexical indices to obtain enough frequency information from relatively short texts. As Tabata (2002) pointed out, the use of lexical indices like parts of speech can alleviate the effect from the contents and clarify the stylistic differences. In this study, the frequencies of the indices are calculated by $j$ Readability, ${ }^{8}$ which quantifies the difficulty of Japanese sentences.

Table 2. Lexical indices used in this study

\begin{tabular}{|c|c|}
\hline \multirow[t]{13}{*}{ Part of Speech } & Interjection (Int.) \\
\hline & Adjectival noun (Ad.N.) \\
\hline & Adjective (Adj.) \\
\hline & Particle (Par.) \\
\hline & Auxiliary verb (Aux.) \\
\hline & Conjunction (Con.) \\
\hline & Pronoun (Pro.) \\
\hline & Verb (Ver.) \\
\hline & Adverb (Adv.) \\
\hline & Proper noun (Pr.N.) \\
\hline & Common noun (Co.N.) \\
\hline & Adnominal (And.) \\
\hline & Other (Oth.) \\
\hline \multirow[t]{4}{*}{ Word types } & Japanese-origin (Jap.) \\
\hline & Chinese-origin (Chi.) \\
\hline & Foreign-origin (For.) \\
\hline & Hybrid (Hyb.) \\
\hline \multirow[t]{3}{*}{ Character types } & Hiragana (Hir.) \\
\hline & Katakana (Kat.) \\
\hline & Kanji (Kan.) \\
\hline \multirow[t]{3}{*}{ Vocabulary Level } & Level 1 (L1) (easiest) \\
\hline & Level 2 (L2) \\
\hline & Level 3 (L3) \\
\hline
\end{tabular}

8 http://jreadability.net/. 
Level 4 (L4)

Level 5 (L5)

Level 6 (L6) (most difficult)

\subsection{Statistical Techniques}

This study primarily applied multiple regression analysis as an analytic method whose purpose is to explain and predict a criterion variable from multiple explanatory variables. The statistical method can be used to identify the explanatory variables that are related to the criterion variable, to describe the relationships between these two types of variables, and to provide an equation for the prediction of the criterion variable from the explanatory variables (Kabacoff 2011). In this study, explanatory variables consist of parts of speech, word types, character types, and vocabulary levels, whereas criterion variables represent the year that a song ranked in the top twenty titles selected by the annual Oricon single chart. Before implementing multiple regression analysis, we identified several pairs of variables that showed a high correlation with each other, and carried out stepwise variable selection based on the Akaike Information Criterion (AIC) to deal with potential multicollinearity.

Regression modeling is instrumental in capturing the chronological changes in language data. Using statistical modeling, S. Tsukamoto (2004) showed that the year of publications of English prose written between the sixteenth and twentieth centuries could be predicted by the frequencies of $w h$-determiners, been, and adjectives. Jin (2009) also pointed out the strong relationship between the year of publications and the frequencies of nominative particles and conjunctive particles in the writings of the famous Japanese novelist Ryunosuke Akutagawa.

\section{Results and Discussion}

\subsection{Correlation Analysis}

The present study began with investigating correlations among all variables, including criterion variables, by calculating the Pearson's product moment correlation coefficient (r). Table 3 lists the top ten high correlation pairs. As this table shows, the highestcorrelation pair among lexical indices is that of Japanese-origin words and Chinese-origin words $(r=-0.99)$, following particles and other parts of speech $(r=-0.98)$ and foreignorigin words and katakana $(r=0.89)$. The lexical index that has the highest correlation with the year of song popularity is kanji $(r=0.78)$. 
Table 3. Correlations between variables (top 10)

\begin{tabular}{lllr}
\hline \multicolumn{1}{c}{ Rank } & \multicolumn{1}{c}{ Variable 1 } & Variable 2 & \multicolumn{1}{c}{$r$} \\
\hline 1 & Japanese-origin & Chinese-origin & -0.99 \\
2 & Particle & Other & -0.98 \\
3 & Foreign-origin & Katakana & 0.89 \\
4 & Verb & Other & -0.89 \\
5 & Verb & Particle & 0.87 \\
6 & Pronoun & Other & -0.85 \\
7 & Particle & Pronoun & 0.83 \\
8 & Auxiliary verb & Other & -0.78 \\
9 & Kanji & Year & 0.78 \\
10 & Particle & Auxiliary verb & 0.75 \\
\hline
\end{tabular}

\subsection{Multiple Regression Analysis}

The next step was to describe the chronological shift in the usages of lexical indices in lyrics by applying multiple regression analysis. Given the highly correlated pairs identified in the previous correlation analysis, a stepwise variable selection using AIC was implemented to cope with the multicollinearity problem. As a result, sixteen variables were selected: (a) adjectival noun, (b) auxiliary verb, (c) conjunction, (d) pronoun, (e) verb, (f) adverb, (g) adnominal, (h) level 2 vocabulary, (i) level 3 vocabulary, (j) level 4 vocabulary, (k) hiragana, (1) katakana, (m) Japanese-origin word, (n) Chinese-origin word, (o) foreign-origin word, and (p) hybrid word (see table 4).

Table 4. Results of multiple regression analysis

\begin{tabular}{lrrrrc}
\hline & \multicolumn{1}{c}{ Estimate } & Standard Error & $t$ value & $p(>|t|)$ & Significance \\
\hline (Intercept) & $-2.900 \mathrm{e}+04$ & $1.304 \mathrm{e}+04$ & -2.23 & 0.04 & $*$ \\
Adjectival noun & $-7.820 \mathrm{e}+00$ & $3.623 \mathrm{e}+00$ & -2.16 & 0.04 & $*$ \\
Auxiliary verb & $3.072 \mathrm{e}+00$ & $1.047 \mathrm{e}+00$ & 2.93 & 0.01 & $* *$ \\
Conjunction & $-3.879 \mathrm{e}+01$ & $1.672 \mathrm{e}+01$ & -2.32 & 0.03 & $*$ \\
Pronoun & $-2.577 \mathrm{e}+00$ & $1.795 \mathrm{e}+00$ & -1.44 & 0.16 & \\
Verb & $-1.917 \mathrm{e}+00$ & $9.938 \mathrm{e}-01$ & -1.93 & 0.07 &
\end{tabular}




\begin{tabular}{lrrrrr} 
Adverb & $4.255 \mathrm{e}+00$ & $2.470 \mathrm{e}+00$ & 1.72 & 0.10 & \\
Adnominal & $6.195 \mathrm{e}+00$ & $5.343 \mathrm{e}+00$ & 1.16 & 0.26 & \\
Level 2 & $1.544 \mathrm{e}+02$ & $5.981 \mathrm{e}+01$ & 2.58 & 0.02 & $*$ \\
Level 3 & $1.902 \mathrm{e}+02$ & $7.471 \mathrm{e}+01$ & 2.55 & 0.02 & $*$ \\
Level 4 & $1.301 \mathrm{e}+02$ & $7.347 \mathrm{e}+01$ & 1.77 & 0.09 & \\
Hiragana & $-1.502 \mathrm{e}+00$ & $9.226 \mathrm{e}-01$ & -1.63 & 0.12 & \\
Katakana & $-2.263 \mathrm{e}+00$ & $9.060 \mathrm{e}-01$ & -2.50 & 0.02 & $*$ \\
Japanese-origin & $3.099 \mathrm{e}+02$ & $1.298 \mathrm{e}+02$ & 2.39 & 0.03 & $*$ \\
Chinese-origin & $3.132 \mathrm{e}+02$ & $1.309 \mathrm{e}+02$ & 2.39 & 0.03 & $*$ \\
Foreign-origin & $3.115 \mathrm{e}+02$ & $1.306 \mathrm{e}+02$ & 2.39 & 0.03 & $*$ \\
Hybrid & $3.010 \mathrm{e}+02$ & $1.299 \mathrm{e}+02$ & 2.32 & 0.03 & $*$ \\
\hline
\end{tabular}

Notes. The columns in this table signify the following: "Estimate" shows regression coefficients; "Standard Error" means standard deviation of variables; " $t$ value" is the result of the $t$-test based on the null hypothesis that a regression coefficient equates to $0 ;$ " $p(>|t|)$ " is called the $p$ value calculated from the $t$ value; and "Significance" shows the significance level $(* *=p<0.01, *=p<0.05)$. "Intercept" refers to the formula of regression line.

The coefficient of determination was 0.93 , and the adjusted coefficient of determination was 0.83 , showing that the null hypothesis that all regression coefficients are 0 was rejected $(F=21.98)$. It was found that there was a strong relationship between the year of song popularity and lexical usage rates of adjectival noun, auxiliary verb, conjunction, level 2 vocabulary, level 3 vocabulary, hiragana, katakana, Japanese-origin word, Chinese-origin word, foreign-origin word, and hybrid word, by observing the $p$ values of the regression coefficients $(p<0.05)$. What is to be noted is that all four categories of word types have a significant connection with the timing of song popularity. As has already been mentioned above, regression modeling can be exploited to predict the criterion variable from the explanatory variables as well as to describe the relationships between explanatory and criterion variables. Therefore, we predicted the year of song popularity by applying multiple regression analysis based on lexical indices. Given the sample size of our dataset (858 songs), two-thirds of the randomly selected data were utilized to generate a statistical model for the prediction of the year, whereas the other one-third was used to validate the model. The results of the analysis showed that the coefficient of determination and adjusted coefficient of determination were 0.92 and 0.86 , respectively, while the $F$ value was 16.58 . The average difference between the actual and predicted year of song popularity was only 5.75 . The results clearly demonstrate that the methodology of combining lexical indices and regression analysis is effective in 
tracking the chronological changes in language use in lyrics.

\subsection{Chronological changes in lexical indices}

The results of multiple regression analysis (see table 4) show that there was a strong relationship between lexical usage (e.g., Japanese-, Chinese-, and foreign-origin words) and the year of song popularity. This section, therefore, closely observes the chronological shift of lexical indices. To begin with, figure 1 shows the chronological changes in the usages of Chinese-origin words from 1977 to $2015 .{ }^{9}$ The horizontal axis shows years, whereas the vertical axis signifies the relative frequency of usage. It can be seen that the usage of Chinese-origin words gradually increases over time. By contrast, non-Chinese foreign-origin word usage decreases after 1990, although it increases again in 2010. Moreover, frequency change patterns in word types corresponded with those in character types. As figures 3 and 4 elucidate, the relative frequency of kanji has a gradual rise, whereas that of katakana has a considerable fall after $1990 .{ }^{10}$

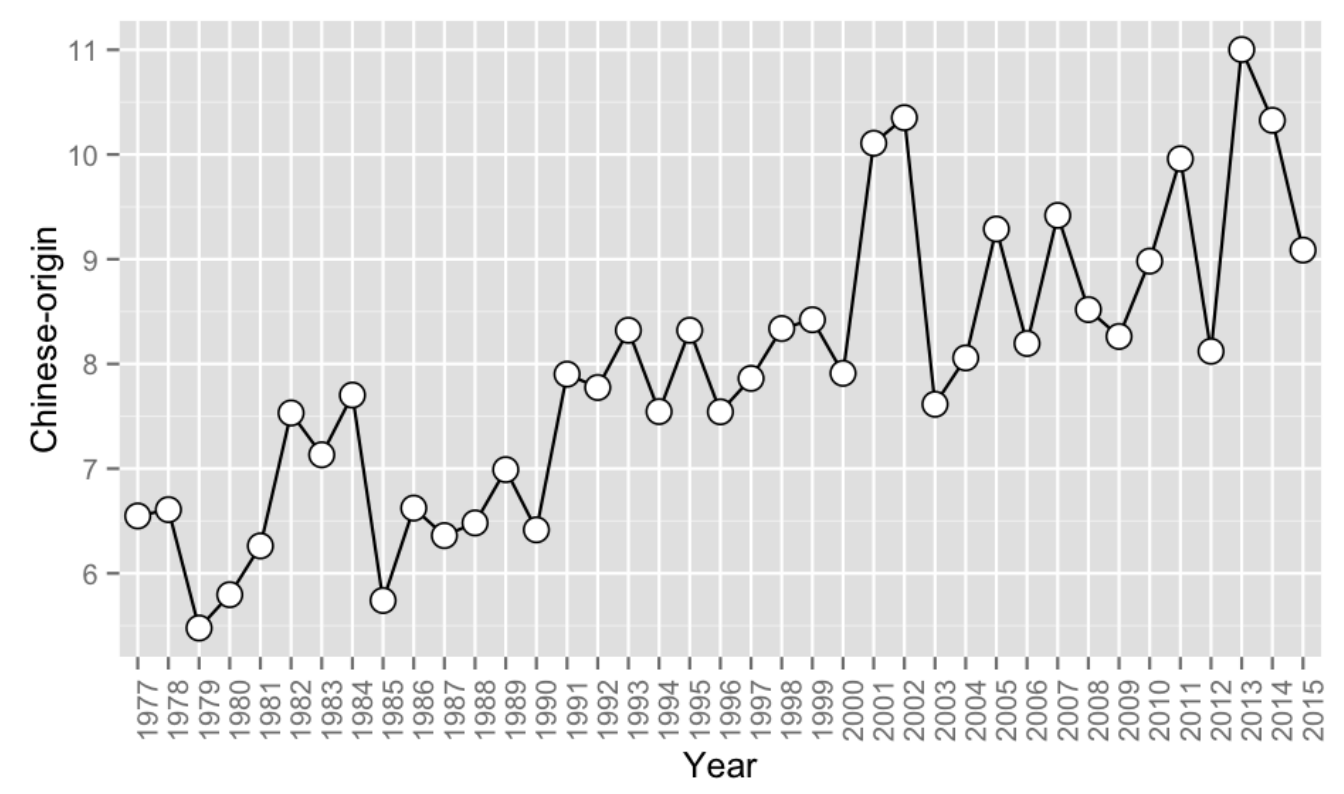

Figure 1. Chronological shift in the relative frequency of Chinese-origin words

9 The relative frequency of Chinese-origin words in 1976 can be regarded as an outlier that blurs the frequency change pattern over the past four decades (see appendix B). Thus, we did not use the frequency of the year for the visualization in figure 1.

10 The increase of kanji may be a general tendency that is partially due to the widespread use of word processors. 


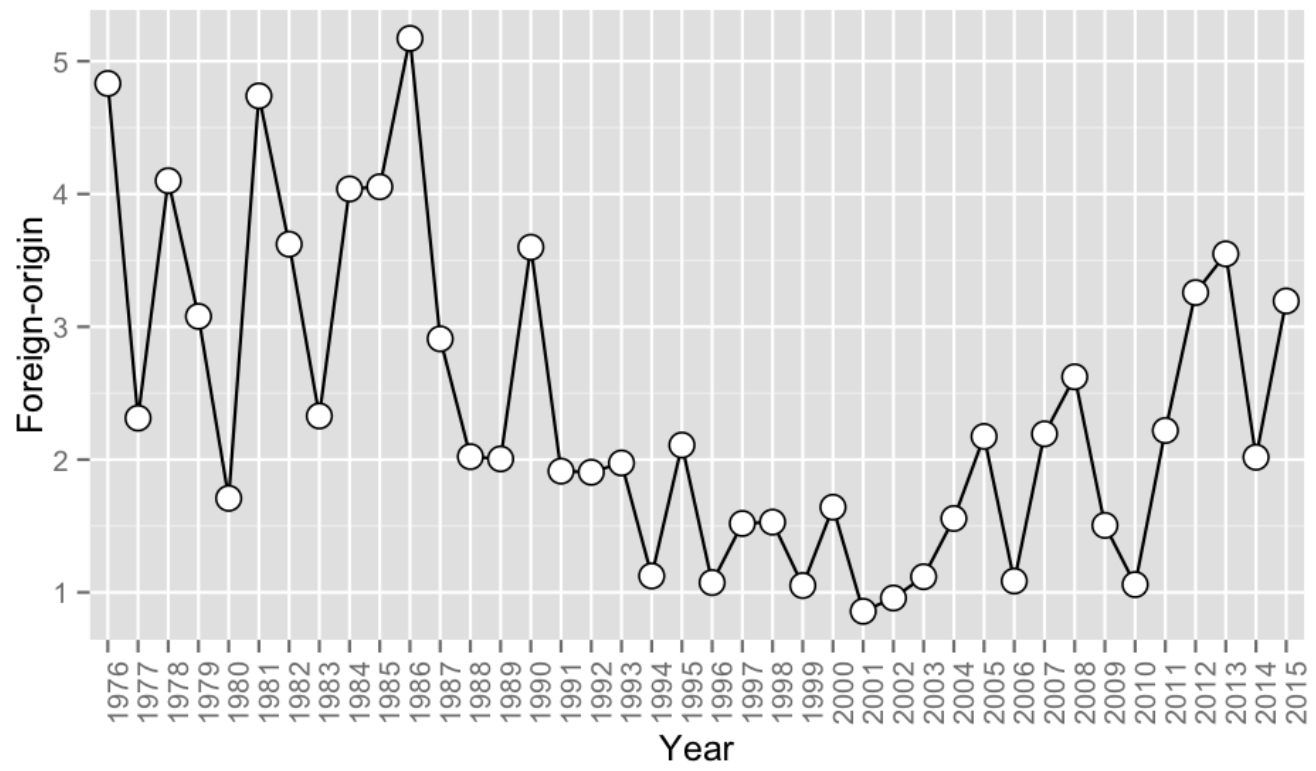

Figure 2. Chronological shift in the relative frequency of foreign-origin words

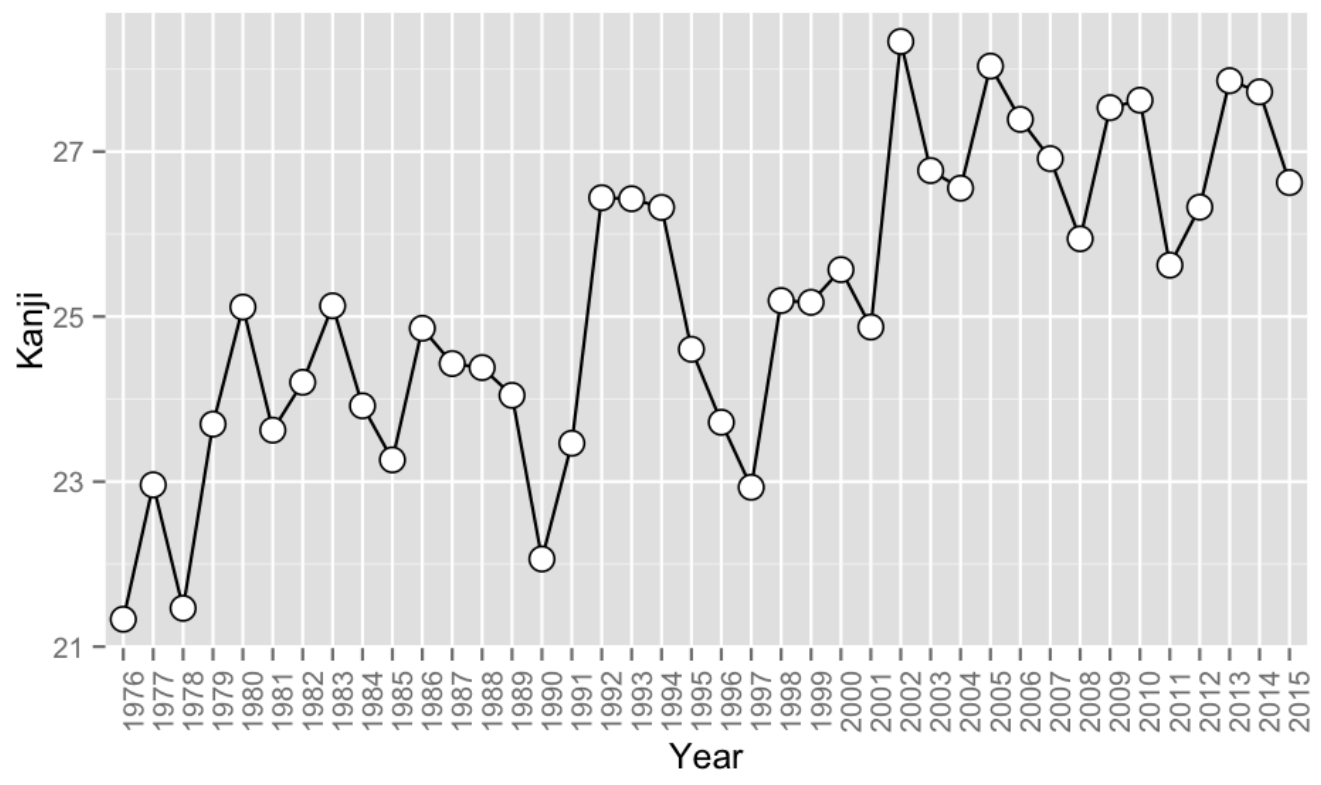

Figure 3. Chronological shift in the relative frequency of kanji 


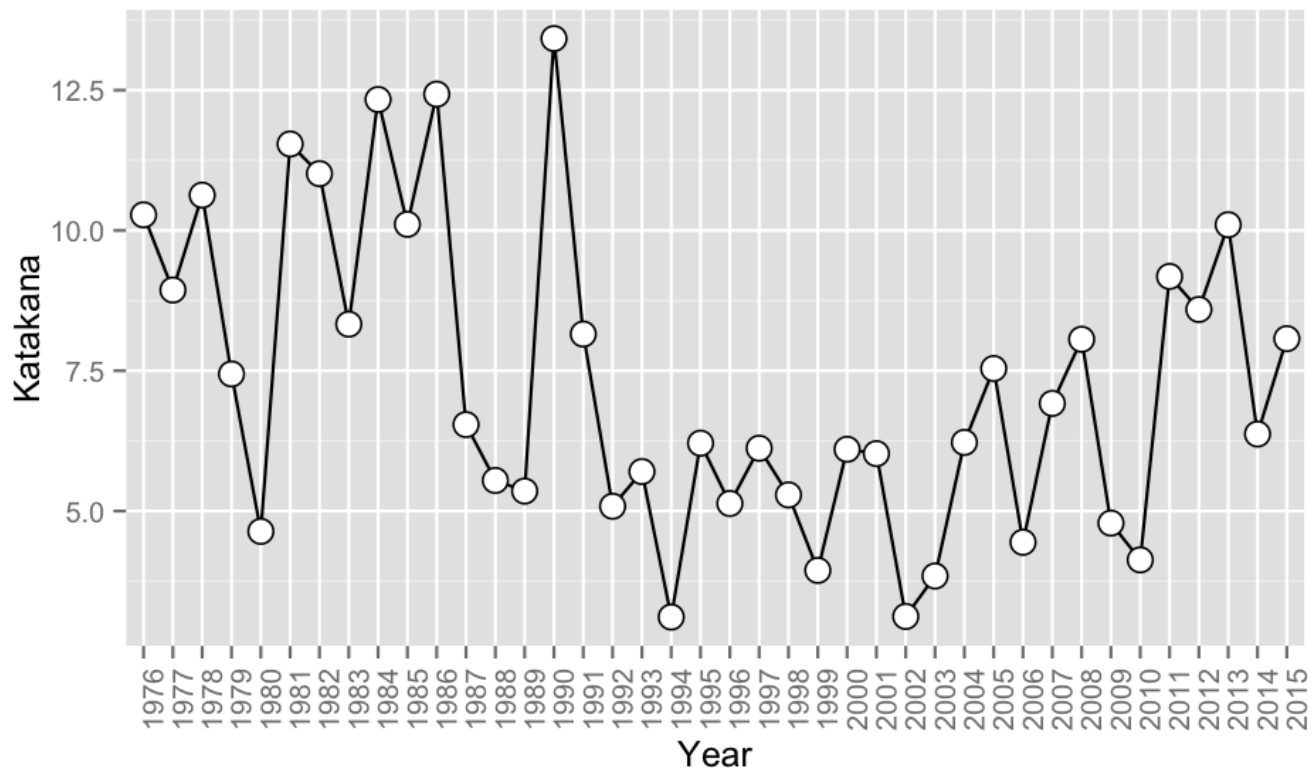

Figure 4. Chronological shift in the relative frequency of katakana

Qualitative analysis of the lyrics of hit songs highlights the decline of foreignorigin words and katakana. These linguistic features were more frequently used in the 1970s and 80s than in later decades. For example, Julia ni Heartbreak (Heart broken by Julia) by Checkers (the top single on the 1985 Oricon chart) and CHA-CHA-CHA by Akemi Ishii (the top single in 1986) displayed the large number of foreign-origin words and katakana: ${ }^{1} 1$

(1) キャンドル・ライト (candlelight) が

ガラス (glass) のピアス (earrings) に反射けて滲む

お前彼の腕の中踊る

傷心 (ハートブレイク) (heartbreak) Saturday Night

悲しいキャロル (carol) がショーウインドウ (show window) で 銀の雪に変わつたよ

(Julia ni Heartbreak)

(2) 街で噂の

幸くち

セクシー・ギャル (sexy girl)

はねつける

スパイシー・ギャル (spicy girl)

花の金曜日 (ウィークエンド) (weekend)

匂いも吾アンキー・ナイト (funky night)

11 Foreign-origin words in Japanese lyrics were highlighted in underlines. 
(CHA-CHA-CHA)

Recently, however, J-pop songs have not used either foreign-origin words or foreign languages with a high level of frequency in their lyrics, even though the titles are in English, such as Believe by Arashi (the top single in 2009) and Beginner by AKB48 (the top single in 2010). Furthermore, the titles of seventeen songs by Ayumi Hamasaki charted in the top twenty from 1999 to 2005 were all in English, ${ }^{12}$ but the frequencies of foreign-origin words and foreign languages are very low in the lyrics, which made them rather classical in style (Misaki 2002).

The changes in the usage of word and character types reflect changes in some values among Japanese people. During the 1970s and 1980s, foreign languages and foreignorigin words were used to create "cool" Western images that many Japanese people admired. However, as Japanese popular culture matured, the use of these indices has declined. A dramatic change in the usage of word and character types occurred around 1990, when the Showa era ended and the bubble economy burst in Japan - a turning point in cultural trends that corresponds with historically significant political and economic events. Additionally, the increase of Japanese- and Chinese-origin words in popular songs may be connected with the Galapagos syndrome of the Japanese music industry as well as the rightward trends seen in Japanese youth culture after the 1990s.

Another noteworthy shift in the language use of Japanese popular songs can be seen in the vocabulary levels used in the lyrics. As regression coefficients shown in table 4 indicate, the proportions of level 2 and 3 words in Japanese popular songs significantly increased over the past four decades, which represents a decrease in the proportions of more difficult words. In addition, the results of regression analysis show an increase in adjectival nouns and conjunctions and a decrease in auxiliary verbs. These trends in the use of parts of speech represent the preference for conveying emotion and feelings instead of describing concrete episodes in the lyrics.

\section{Conclusion}

This study compared the usages of 26 lexical indices in 858 Japanese popular songs released in a forty-year period from 1976 to 2015, and investigated the chronological shifts in language usage. The results showed that the frequencies of different word types and character types changed drastically before and after 1990. Particularly, it was shown

\footnotetext{
12 One of them, “A Song Is Born," produced in 2002, was a duet with KEIKO. Two songs in a single album were counted as one.
} 
that the frequencies of foreign-origin words and katakana diminished, while the frequencies of Chinese-origin words and kanji increased. Concerning parts of speech and vocabulary levels, the usages of auxiliary verbs as well as level 2 and 3 words became more prominent, whereas the frequencies of adjectival nouns and conjunctions decreased. These outcomes are derived from systematic data and statistical methods, thus providing objective resources for sociological research on Japanese contemporary culture. For further research, it is necessary to consider both the music genres and the genders of the singers, considering how lyrics vary according to these elements (Kitagawa 1999). What is more, topic modeling can be useful for carefully examining the social and historical backgrounds within which each song was created.

\section{Acknowledgments}

Earlier versions of the present study were presented at the Jinmoncom Symposium 2015 and the International Quantitative Linguistic Conference 2016. This work was supported by Grants-in-Aid for Scientific Research Grant Numbers 26730162.

\section{References}

Amagasa, Misaki. 2014. "Hitto songu no kashi no tekisuto bunseki" [A Text Analysis of Popular Song Lyrics]. Unpublished BA thesis. Tokyo: Department of Media and Communications, Faculty of Sociology, Toyo University.

Bértoli-Dutra, Patrícia. 2014. "Multi-Dimensional Analysis of Pop Songs." In MultiDimensional Analysis, 25 Years On: A Tribute to Douglas Biber, edited by Tony Berber Sardinha and Marcia Veirano Pinto, 149-76. Amsterdam: John Benjamins.

Carey, James T. 1969. "Changing Courtship Patterns in the Popular Song." American Journal of Sociology 74(6): 720-31.

Fujikake, Kazumi, Eri Nishimura, Makoto Suganuma, Sayuri Taga, and Chiaki Sawayanagi. 1994. "Gendai ryukōka kashi no utsurikawari: 1970-nendai to 1992-nen hitto kyoku no hikaku kara" [The Change of the Contemporary Japanese Popular Song Lyrics: A Comparison between the Popular Songs Produced in the 1970s and 1992]. Chube University Women's College Gazette 5: 49-60.

Fujikawa, Daisuke. 1999. "Hitto kyoku no henka to kodomotachi no Jōkyō" [Changes in Popular Songs and Children's Conditions]. In Treatises and Studies by the Faculty of Kinjo Gakuin University. Studies in Humanities 32: 119-32. 
Horton, Donald. 1957. "The Dialogue of Courtship in Popular Songs.” American Journal of Sociology 62(6): 569-78.

Ito, Masamitsu. 1997-2000. "Yu-min no Gengogaku." (1)-(46) [Linguistics in the Lyrics of Yumi Matsutoya]. Nihongo-gaku [Japanese Linguistics] 16(4)-20(8).

Jin, Mingzhe. 2009. "Bunsho no Shippitsu Jiki no Suitei: Akutagawa Ryunosuke no Sakuhin wo Rei Toshite" [Predicting When a Text Was Written: A Case Study of the Writings by Japanese Novelist Ryunosuke Akutagawa]. Kōdō keiryōgaku (The Journal of Behaviormetrics) 36(2): 89-103.

Kabacoff, Robert I. 2011. R in Action: Data Analysis and Graphics with R. Shelter Island, New York: Manning.

Kabashima, Tadao, and Akiko Jugaku. 1965. Buntai no kagaku [Science of Styles]. Kyoto: Sogeisha.

Kayane, Shigeru. 2002. "Keizaiteki kanten kara miru nichibei no hitto kyoku no kashi kōozō to sono hōsokusei" [The Stylistic Structures and Rules of Japanese and American Popular Songs: From an Economic Point of View]. The Students' Journal of the Economic Association, Kanazawa University 21: 83-96.

Kinjo, Katsuya. 2013. "Makihara Noriyuki no Kashi no Sūryoteki Bunseki: Kimi ga warau toki kimi no mune ga itamanai yō ni kara heart to heart Made" [Quantitative Analysis of the Lyrics Written by Noriyuki Makihara: From So that Your Heart Wouldn't Be Hurt When You Smile to Heart to Heart]. Ryudai Review of Euro-American Studies 57: 23-42.

Kitagawa, Junko. 1999. "Nihon no popyura ongaku to jenda eno tenbō" [A Prospect of Japanese Popular Music and Gender]. In Narihibiku sei: nihon no popyura ongaku to jenda [The Echo of Gender: Japanese Popular Music and Gender], edited by J. Kitagawa, 1-30. Tokyo: Keisosha Shobo.

Kobayashi, Kaori, Erina Kano, and Takafumi Suzuki. 2013. "Josei grupu no kashi no keiryō tekisuto bunseki" [Quantitative Text Analysis of the Lyrics Written by Female Groups]. In Proceedings of the 19th Annual Conference of the Association for Natural Language Processing, 338-41. Accessed July 3, 2017. http://www.anlp.jp/proceedings/annual_meeting/2013/pdf_dir/P1-5.pdf.

Kubo, Masatoshi. 1995. "Nyu Myuzic ni Miru Rennai Fukei” [Romantic Sceneries Found in New Music]. In Jōhō shori gakkai kenkyū hōkoku [Research Reports of the Information Processing Society], CH-25, 49-57.

Misaki, Tetsu. 2002. Jei-poppu no nihongo: kashiron [Japanese Language in J-POP Songs: From the Perspective of Lyrics]. Tokyo: Sairyusha.

Mita, Munesuke. 1968. Kindai Nihon no shinjō no rekishi [The History of Sentiment in 
Modern Japan]. Tokyo: Kodansha.

Mizutani, Shizuo. 1982. Sūri gengogaku [Mathematical linguistics]. Tokyo: Baifukan.

Mooney, H. F. 1968. "Popular Music since the 1920s: The Significance of Shifting Taste." American Quarterly 20(1): 67-85. doi:10.2307/2710991.

Powell-Morse, Andrew. 2015. "Lyric Intelligence in Popular Music: A Ten Year Analysis." SeatSmart Blog, May 18. http://seatsmart.com/blog/lyric-intelligence/.

Sako, Teruhito. 2015. "Hitto songu kashi no hensen: 1968-nen kara 2013-nen made" [A Statistical Analysis of the Japanese Hit Song Lyrics Through the Years 19682013]. Jinbungakuho (The Journal of Social Sciences and Humanities) 497: 49-85.

Suzuki, Naoe, and Takashi Yamaguchi. 2000. "Ryūkōka no kashi ni miru gengo no hensen: kako 34-nenkan no hitto kyoku wo toshite" [The Linguistic Change Seen in the Lyrics of Japanese Popular Songs: An Analysis of Hit Songs for the Past 34 Years]. Reports on the Research, Tohoku Seikatsu Bunka College, Mishima Gakuen Women's Junior College 31: 55-65.

Suzuki, Takafumi, and Mai Hosoya. 2014. "Computational Stylistic Analysis of Popular Songs of Japanese Female Singer-Songwriters.” Digital Humanities Quarterly 8(1). Accessed July 3, 2017. http://www.digitalhumanities.org/dhq/vol/8/1/000170/000170.html.

Tabata, Tomoji. 2002. "Investigating Stylistic Variation in Dickens through Correspondence Analysis of Word-Class Distribution." In English Corpus Linguistics in Japan, edited by Toshio Saito, Junsaku Nakamura, and Shunji Yamazaki, 165-82. Amsterdam: Rodopi.

Tsukamoto, Satoru. 2004. "Quantifying Diachronic Change: Part of Speech Analysis from Early Modern to Modern English.” English Corpus Studies 11: 19-36.

Tsukamoto, Taizo. 2014. "Gendaigo tenshi no korokeishon shoko: kashi no naka de tenshi wa donoyouni furumauka" [Collocations of a Contemporary Word for Angel in Japanese: How it Behaves in Lyrics]. Kokugo Kokubungaku Kenkyū (Research on Japanese Language and Literature) 49: 331-41.

Wilkinson, Melvin. 1976. "Romantic Love: The Great Equalizer? Sexism in Popular Music." The Family Coordinator 25(2): 161-66. doi:10.2307/582795.

Yasumoto, Biten. 1958. "Buntai tōkei ni yoru hissha suitei: Uji jūjōo no sakusha ni tsuite" [Predicting the Authors by Stylistic Statistics: Concerning the Authors of the Ten chapters of Uji]. Japanese Psychological Review 2: 147-56.

Yasumoto, Biten. 1965. Bunsho shinrigaku nyūmon [An Introduction to Text Psychology]. Tokyo: Seishin Shobo. 


\section{Appendix A. The relative frequencies of parts of speech}

\begin{tabular}{|c|c|c|c|c|c|c|c|c|c|c|c|c|c|}
\hline \multirow[b]{2}{*}{ Year } & \multicolumn{13}{|c|}{ Parts of speech } \\
\hline & Int. & Ad.N & Adj & Par. & Au.V. & Con. & Pro. & Ver. & Adv. & Pr.N. & Co.N. & And. & Oth. \\
\hline 1976 & 0.59 & 2.49 & 2.49 & 32.72 & 10.65 & 0.11 & 6.45 & 11.87 & 2.56 & 0.78 & 24.81 & 0.67 & 3.82 \\
\hline 1977 & 0.88 & 1.21 & 2.46 & 27.51 & 8.76 & 0.02 & 4.58 & 9.43 & 1.94 & 0.76 & 21.19 & 0.88 & 20.36 \\
\hline 1978 & 0.73 & 1.33 & 2.47 & 29.30 & 8.71 & 0.13 & 4.94 & 9.12 & 2.02 & 0.73 & 22.54 & 0.67 & 17.29 \\
\hline 1979 & 0.30 & 0.70 & 2.08 & 24.50 & 5.56 & 0.12 & 3.60 & 9.26 & 1.71 & 0.61 & 22.05 & 0.70 & 28.81 \\
\hline 1980 & 0.44 & 1.48 & 2.79 & 29.20 & 7.56 & 0.09 & 4.14 & 10.35 & 1.82 & 0.21 & 23.73 & 1.26 & 16.95 \\
\hline 1981 & 0.22 & 1.36 & 3.02 & 25.13 & 6.14 & 0.13 & 3.19 & 8.75 & 1.81 & 0.79 & 21.92 & 0.55 & 27.00 \\
\hline 1982 & 0.37 & 1.27 & 2.88 & 25.82 & 7.18 & 0.18 & 3.45 & 8.77 & 1.83 & 0.55 & 22.05 & 0.58 & 25.06 \\
\hline 1983 & 0.15 & 1.39 & 3.08 & 25.90 & 8.57 & 0.08 & 3.38 & 9.10 & 2.21 & 0.83 & 21.69 & 0.64 & 22.98 \\
\hline 1984 & 0.69 & 1.40 & 2.23 & 24.87 & 7.85 & 0.09 & 2.73 & 8.78 & 1.95 & 0.82 & 24.14 & 0.52 & 23.95 \\
\hline 1985 & 0.31 & 0.60 & 1.81 & 19.03 & 6.28 & 0.20 & 2.48 & 6.95 & 0.98 & 0.37 & 19.08 & 0.51 & 41.40 \\
\hline 1986 & 0.30 & 1.08 & 1.57 & 19.04 & 5.62 & 0.13 & 2.18 & 6.69 & 1.27 & 0.29 & 20.80 & 0.63 & 40.42 \\
\hline 1987 & 0.12 & 1.33 & 2.29 & 24.47 & 8.20 & 0.15 & 2.64 & 9.91 & 1.34 & 0.28 & 21.15 & 0.60 & 27.52 \\
\hline 1988 & 0.38 & 1.18 & 2.48 & 23.74 & 8.41 & 0.08 & 3.23 & 9.43 & 1.60 & 0.42 & 20.41 & 0.78 & 27.86 \\
\hline 1989 & 0.18 & 0.82 & 2.44 & 23.64 & 7.31 & 0.09 & 2.66 & 9.00 & 1.43 & 0.19 & 21.56 & 0.78 & 29.90 \\
\hline 1990 & 0.60 & 0.88 & 1.73 & 20.68 & 6.35 & 0.02 & 2.13 & 7.63 & 1.76 & 0.47 & 18.85 & 0.65 & 38.24 \\
\hline 1991 & 0.22 & 1.18 & 1.77 & 21.38 & 7.13 & 0.11 & 3.08 & 8.33 & 2.12 & 0.20 & 19.34 & 1.01 & 34.13 \\
\hline 1992 & 0.13 & 1.43 & 2.34 & 25.24 & 8.80 & 0.11 & 4.03 & 9.35 & 2.14 & 0.09 & 19.94 & 0.75 & 25.65 \\
\hline 1993 & 0.18 & 1.69 & 2.69 & 25.66 & 9.35 & 0.15 & 3.84 & 10.71 & 2.39 & 0.27 & 19.76 & 1.01 & 22.29 \\
\hline 1994 & 0.13 & 1.28 & 2.47 & 23.49 & 8.77 & 0.15 & 3.54 & 8.47 & 1.58 & 0.15 & 16.99 & 0.86 & 32.13 \\
\hline 1995 & 0.38 & 1.18 & 2.64 & 25.93 & 9.25 & 0.17 & 3.80 & 9.18 & 2.27 & 0.18 & 21.62 & 0.80 & 22.59 \\
\hline 1996 & 0.22 & 1.11 & 2.45 & 21.75 & 7.59 & 0.10 & 3.05 & 7.93 & 1.58 & 0.30 & 17.62 & 0.77 & 35.53 \\
\hline 1997 & 0.14 & 1.44 & 2.81 & 24.60 & 8.70 & 0.06 & 3.32 & 8.55 & 1.58 & 0.20 & 17.89 & 0.63 & 30.08 \\
\hline 1998 & 0.22 & 1.44 & 2.86 & 25.97 & 9.89 & 0.09 & 3.28 & 10.97 & 1.68 & 0.14 & 20.49 & 0.90 & 22.08 \\
\hline 1999 & 0.27 & 1.27 & 3.23 & 23.34 & 8.65 & 0.07 & 2.78 & 8.38 & 2.15 & 0.19 & 18.45 & 0.77 & 30.44 \\
\hline 2000 & 1.37 & 1.44 & 1.76 & 18.77 & 7.13 & 0.09 & 2.48 & 6.37 & 1.76 & 0.19 & 17.14 & 0.85 & 40.63 \\
\hline 2001 & 0.41 & 0.96 & 2.53 & 23.60 & 8.62 & 0.17 & 3.57 & 8.36 & 3.36 & 0.12 & 20.29 & 0.86 & 27.16 \\
\hline 2002 & 0.31 & 0.78 & 1.72 & 18.15 & 5.54 & 0.16 & 2.80 & 6.89 & 2.09 & 0.26 & 16.91 & 1.12 & 43.28 \\
\hline 2003 & 0.64 & 1.28 & 2.95 & 31.18 & 10.18 & 0.30 & 4.89 & 10.73 & 3.05 & 0.23 & 21.15 & 1.30 & 12.13 \\
\hline 2004 & 0.29 & 1.62 & 2.96 & 24.83 & 9.06 & 0.11 & 4.52 & 9.76 & 2.42 & 0.18 & 21.29 & 1.03 & 21.92 \\
\hline 2005 & 0.54 & 0.77 & 1.93 & 21.91 & 7.42 & 0.14 & 3.16 & 8.90 & 1.61 & 0.36 & 19.46 & 1.00 & 32.80 \\
\hline 2006 & 0.21 & 1.19 & 2.30 & 27.03 & 9.50 & 0.08 & 4.24 & 10.80 & 1.96 & 0.25 & 19.30 & 1.03 & 22.12 \\
\hline
\end{tabular}


Investigating the Chronological Variation of Popular Song Lyrics Through Lexical Indices

\begin{tabular}{llllllllllllll}
\hline 2007 & 1.32 & 1.15 & 2.49 & 25.75 & 8.63 & 0.05 & 3.63 & 10.75 & 3.06 & 0.72 & 18.98 & 1.00 & 22.47 \\
2008 & 0.44 & 1.11 & 2.00 & 23.52 & 7.90 & 0.10 & 3.71 & 8.90 & 2.20 & 0.63 & 19.76 & 1.06 & 28.68 \\
2009 & 0.42 & 1.29 & 2.22 & 24.75 & 8.96 & 0.11 & 3.70 & 10.09 & 2.10 & 0.17 & 19.47 & 1.07 & 25.64 \\
2010 & 0.15 & 1.02 & 1.37 & 18.10 & 5.98 & 0.09 & 2.90 & 6.89 & 1.72 & 0.11 & 17.72 & 0.78 & 43.17 \\
2011 & 0.23 & 1.33 & 2.01 & 24.00 & 8.30 & 0.09 & 3.79 & 8.04 & 2.47 & 0.60 & 18.98 & 1.02 & 29.15 \\
2012 & 0.18 & 1.19 & 2.05 & 21.14 & 8.34 & 0.07 & 2.95 & 7.37 & 2.23 & 0.22 & 18.87 & 1.00 & 34.38 \\
2013 & 0.34 & 1.22 & 2.44 & 23.65 & 8.76 & 0.04 & 3.12 & 8.87 & 1.93 & 0.13 & 20.90 & 1.22 & 27.38 \\
2014 & 0.24 & 1.77 & 3.23 & 31.15 & 11.70 & 0.12 & 4.32 & 10.73 & 1.87 & 0.26 & 22.21 & 0.76 & 11.63 \\
2015 & 0.28 & 0.92 & 2.26 & 25.23 & 9.26 & 0.09 & 3.39 & 9.07 & 2.07 & 0.20 & 19.23 & 1.01 & 26.99 \\
\hline
\end{tabular}

Appendix B. The relative frequencies of word types, character types, and

\begin{tabular}{|c|c|c|c|c|c|c|c|c|c|c|c|c|c|}
\hline \multirow[b]{2}{*}{ Year } & \multicolumn{4}{|c|}{ Word types } & \multicolumn{3}{|c|}{ Character types } & \multicolumn{6}{|c|}{ Vocabulary levels } \\
\hline & Jap. & Chi. & For. & Hyb. & Hir. & Kat. & Kan. & L1 & L2 & L3 & $\mathrm{L} 4$ & L5 & L6 \\
\hline 1976 & 27.88 & 63.55 & 4.83 & 3.25 & 68.39 & 10.28 & 21.33 & 0.37 & 0.22 & 0.22 & 0.14 & 0.05 & 0.01 \\
\hline 1977 & 89.77 & 6.55 & 2.31 & 1.37 & 68.10 & 8.94 & 22.96 & 33.28 & 22.20 & 22.37 & 16.02 & 4.89 & 1.25 \\
\hline 1978 & 88.40 & 6.61 & 4.10 & 0.89 & 67.91 & 10.63 & 21.47 & 30.85 & 22.64 & 21.97 & 16.71 & 6.54 & 1.29 \\
\hline 1979 & 90.51 & 5.48 & 3.08 & 0.93 & 68.86 & 7.44 & 23.70 & 29.66 & 25.47 & 21.89 & 15.46 & 6.78 & 0.73 \\
\hline 1980 & 90.73 & 5.80 & 1.71 & 1.77 & 70.25 & 4.64 & 25.12 & 28.53 & 26.24 & 21.92 & 17.47 & 5.09 & 0.76 \\
\hline 1981 & 88.18 & 6.26 & 4.74 & 0.82 & 64.84 & 11.54 & 23.62 & 28.41 & 23.16 & 22.29 & 18.58 & 6.85 & 0.72 \\
\hline 1982 & 87.54 & 7.53 & 3.62 & 1.30 & 64.78 & 11.01 & 24.20 & 27.57 & 23.01 & 23.65 & 18.28 & 6.73 & 0.77 \\
\hline 1983 & 89.13 & 7.13 & 2.33 & 1.41 & 66.54 & 8.33 & 25.13 & 30.36 & 24.48 & 21.08 & 16.86 & 6.02 & 1.19 \\
\hline 1984 & 86.43 & 7.70 & 4.04 & 1.83 & 63.75 & 12.33 & 23.92 & 29.52 & 24.24 & 21.83 & 17.24 & 6.44 & 0.72 \\
\hline 1985 & 89.01 & 5.74 & 4.05 & 1.19 & 66.63 & 10.11 & 23.26 & 27.22 & 23.12 & 24.67 & 18.44 & 5.85 & 0.71 \\
\hline 1986 & 86.38 & 6.62 & 5.17 & 1.82 & 62.71 & 12.43 & 24.86 & 26.23 & 21.76 & 23.65 & 20.67 & 6.57 & 1.13 \\
\hline 1987 & 89.45 & 6.36 & 2.91 & 1.28 & 69.03 & 6.54 & 24.43 & 25.17 & 22.53 & 24.14 & 20.57 & 6.51 & 1.07 \\
\hline 1988 & 89.97 & 6.48 & 2.02 & 1.53 & 70.07 & 5.54 & 24.38 & 24.84 & 22.33 & 26.31 & 17.90 & 7.22 & 1.40 \\
\hline 1989 & 89.43 & 6.99 & 2.01 & 1.57 & 70.60 & 5.36 & 24.05 & 29.41 & 22.51 & 21.30 & 17.66 & 8.30 & 0.81 \\
\hline 1990 & 88.92 & 6.42 & 3.60 & 1.06 & 64.52 & 13.42 & 22.06 & 27.12 & 23.20 & 24.41 & 18.48 & 6.26 & 0.52 \\
\hline 1991 & 88.42 & 7.90 & 1.91 & 1.76 & 68.38 & 8.15 & 23.46 & 25.64 & 26.04 & 24.59 & 16.87 & 6.64 & 0.22 \\
\hline 1992 & 88.62 & 7.77 & 1.90 & 1.70 & 68.47 & 5.09 & 26.44 & 27.15 & 27.91 & 22.44 & 17.32 & 4.63 & 0.55 \\
\hline 1993 & 88.37 & 8.32 & 1.97 & 1.34 & 67.87 & 5.70 & 26.43 & 28.10 & 23.46 & 23.57 & 17.60 & 6.55 & 0.72 \\
\hline 1994 & 89.79 & 7.55 & 1.12 & 1.54 & 70.57 & 3.11 & 26.32 & 27.18 & 26.06 & 23.06 & 17.91 & 5.48 & 0.30 \\
\hline 1995 & 88.35 & 8.32 & 2.11 & 1.22 & 69.19 & 6.21 & 24.60 & 29.00 & 25.52 & 22.82 & 15.77 & 6.21 & 0.68 \\
\hline 1996 & 90.18 & 7.54 & 1.07 & 1.20 & 71.15 & 5.13 & 23.72 & 28.35 & 25.40 & 22.82 & 16.56 & 6.26 & 0.60 \\
\hline 1997 & 89.15 & 7.86 & 1.52 & 1.46 & 70.95 & 6.12 & 22.93 & 28.31 & 26.58 & 22.07 & 16.63 & 5.64 & 0.78 \\
\hline
\end{tabular}


Investigating the Chronological Variation of Popular Song Lyrics Through Lexical Indices

\begin{tabular}{rrrrrrrrrrrrrrr}
\hline 1998 & 88.69 & 8.34 & 1.53 & 1.44 & 69.52 & 5.29 & 25.19 & 25.87 & 25.57 & 23.13 & 17.76 & 7.04 & 0.63 \\
1999 & 89.00 & 8.42 & 1.05 & 1.52 & 70.89 & 3.94 & 25.17 & 28.46 & 26.08 & 23.10 & 16.35 & 5.36 & 0.66 \\
2000 & 89.00 & 7.91 & 1.64 & 1.45 & 68.33 & 6.10 & 25.57 & 27.89 & 24.83 & 23.48 & 18.08 & 5.04 & 0.67 \\
2001 & 86.80 & 10.11 & 0.86 & 2.23 & 69.10 & 6.02 & 24.87 & 26.73 & 24.84 & 23.47 & 19.16 & 5.54 & 0.26 \\
2002 & 87.58 & 10.35 & 0.96 & 1.11 & 68.54 & 3.12 & 28.33 & 32.94 & 23.84 & 21.46 & 15.94 & 5.61 & 0.22 \\
2003 & 90.40 & 7.61 & 1.12 & 0.87 & 69.39 & 3.84 & 26.77 & 28.65 & 27.40 & 22.39 & 15.19 & 5.56 & 0.82 \\
2004 & 88.99 & 8.06 & 1.56 & 1.40 & 67.22 & 6.22 & 26.56 & 24.48 & 27.41 & 23.83 & 17.89 & 5.65 & 0.73 \\
2005 & 87.17 & 9.29 & 2.17 & 1.37 & 64.43 & 7.54 & 28.04 & 27.69 & 24.34 & 22.42 & 18.72 & 5.69 & 1.14 \\
2006 & 89.66 & 8.20 & 1.09 & 1.06 & 68.17 & 4.44 & 27.39 & 26.03 & 24.70 & 22.61 & 20.56 & 5.63 & 0.47 \\
2007 & 86.34 & 9.42 & 2.19 & 2.05 & 66.17 & 6.92 & 26.91 & 28.21 & 24.85 & 22.73 & 16.65 & 6.84 & 0.72 \\
2008 & 87.56 & 8.52 & 2.62 & 1.30 & 66.00 & 8.06 & 25.94 & 29.58 & 23.52 & 24.42 & 17.71 & 4.32 & 0.45 \\
2009 & 89.18 & 8.26 & 1.50 & 1.06 & 67.68 & 4.78 & 27.53 & 25.59 & 26.11 & 23.09 & 19.06 & 5.63 & 0.53 \\
2010 & 88.61 & 8.98 & 1.06 & 1.35 & 68.25 & 4.13 & 27.62 & 25.87 & 25.03 & 24.00 & 19.33 & 5.40 & 0.37 \\
2011 & 86.41 & 9.96 & 2.22 & 1.41 & 65.20 & 9.18 & 25.62 & 27.85 & 23.99 & 24.47 & 18.22 & 5.04 & 0.42 \\
2012 & 87.28 & 8.12 & 3.26 & 1.34 & 65.08 & 8.59 & 26.33 & 28.02 & 25.10 & 22.27 & 18.89 & 5.33 & 0.38 \\
2013 & 84.10 & 11.00 & 3.55 & 1.35 & 62.04 & 10.10 & 27.86 & 0.24 & 0.26 & 0.23 & 0.19 & 0.07 & 0.01 \\
2014 & 86.52 & 10.33 & 2.02 & 1.14 & 65.90 & 6.37 & 27.72 & 0.27 & 0.25 & 0.24 & 0.18 & 0.06 & 0.01 \\
2015 & 86.59 & 9.09 & 3.19 & 1.13 & 65.30 & 8.07 & 26.62 & 0.27 & 0.26 & 0.23 & 0.18 & 0.06 & 0.00 \\
\hline
\end{tabular}

